Indonesian Journal of Physics

Vol 19 No. 3, July 2008

\title{
Focal Mechanism of Volcano-tectonic Earthquakes at Merapi Volcano, Indonesia
}

\author{
Sri Hidayati ${ }^{1)}$, Kazuhiro Ishihara ${ }^{2)}$, Masato Iguchi ${ }^{2)}$, and Antonius Ratdomopurbo ${ }^{1)}$ \\ 1) Center for Volcanology and Geological Hazard Mitigation, \\ Jl. Diponegoro 57 Bandung 40122, Indonesia \\ 2) Sakurajima Volcano Research Center, DPRI, Kyoto University, \\ Sakurajima Yokoyamacho, Kagoshima 891-1419, Japan \\ e-mail address: ichi@vsi.esdm.go.id
}

\begin{abstract}
Merapi (2968 m), located in central Java, is one of the most active and dangerous volcanoes in Indonesia. The volcano has repeated episodes of dome growth and collapse, producing pyroclastic flows during historical time. Volcano-tectonic (VT) earthquakes have been classified into deep (VTA) and shallow one (VTB). Since August 2000, number of VT events $(M=1.0-1.6)$ had increased, and pyroclastic flows have successively occurred from the middle of January, 2001. The focal zone vertically extends to about $4 \mathrm{~km}$ deep beneath the summit. VTA events are located at the depth 2.2-4.1 km and the VTB ones at the depth shallower than $1.3 \mathrm{~km}$. An aseismic zone is observed around 1.3-2.2 $\mathrm{km}$ deep between the hypocenter zones of the two types of VT earthquakes, interpreted as shallow magma storage.

Focal mechanism of VT events was estimated by using both polarity and amplitude of P-wave first motions at 4 seismic stations, assuming double couple mechanism and homogenous medium. Determined focal mechanisms for VTA events are of normal-fault types. VTA events might originate by increase in horizontal tension when magma rose up from deeper portion. Orientation of their T-axes is nearly horizontal in NEE-SWW direction which might be affected by the E-W regional tectonic stress.

As for the VTB, normal fault types dominate the deep VTB zone, while at the shallow part, both reverse fault and normal fault types are originated. The pressure increases at shallow magma storage may cause generation of deep $V T B$ events of normal fault types. As VTB events frequently originated, corresponding to increase of multiphase (MP) events which are related to growth of lava dome, shallow VTB events of reverse fault type might be generated by horizontal compression related to pressure decrease in magma conduit due to extrusion of lava and gases, and occasionally by pressure increase at the shallow part due to accumulation of magma or volcanic gases.
\end{abstract}

Keywords: Merapi volcano, VT earthquakes, Focal mechanism, Eruptive activity.

\section{Introduction}

Merapi is one of the most active and dangerous volcanoes in Indonesia. The volcano is located in central Java, about $25 \mathrm{~km}$ north of the city of Yogyakarta (Figure 1). The summit, which is about $2968 \mathrm{~m}$ above sea level covered by andesitic lava flows and domes. During historical time, the volcano has frequently erupted and the eruption style is characterized by dome growth and collapse, subsequently producing pyroclastic flows. The eruptive activity generally continues for several years after dormant periods of 7-12 years. Recent eruptive episode started in 1992 and eruptions occurred every year until 1998. Volcanic activity declined after the eruption in July 1998 and seismicity was kept low level for two years. Seismic activity resumed in August 2000 and the eruption generated series of pyroclastic flows in mid January to February 2001, traveling down to western flank of the volcano.

Center for Volcanology and Geological Hazard Mitigation (CVGHM) has operated a seismic network since 1982 on the volcano to monitor volcanic activity. The data gathered from the network enable classification of Merapi's seismic events into volcano-tectonic (VT) earthquake, multiphase (MP) event associated with lava dome formation, low frequency (LF) earthquake, volcanic tremor and 'guguran,1) . 'Guguran' is seismic event related to rocks falling down from lava domes. Pyroclastic flows are recognized through visual and seismic observation as successive generation of rockfalls of large amplitude.

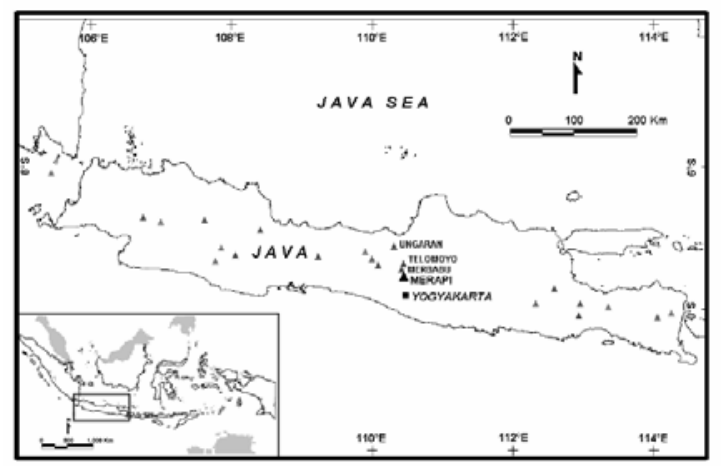

Figure 1. Location map of Merapi volcano in Central Java. Solid triangle denotes Merapi volcano, and the smaller ones do other active volcanoes. Yogyakarta City is indicated by a solid square. 
VT earthquakes originating at Merapi volcano can be distinguished into deep (VTA) and shallow one (VTB). An aseismic zone between VTA and VTB zones is postulated as the manifestation of small magma chamber ${ }^{1)}$ where magma is stored temporarily before being extruded to the surface. Moreover, occurrence of VT earthquakes preceded eruptions of 1984 and $1992^{2)}$.

Seismic and ground-tilt precursors prior to the eight major eruptive episodes between 1991 and 1998 have been examined ${ }^{3)}$. The 1992 eruption, the initial eruption of that active period, was preceded by remarkable number of VT events, while the following 7 eruptions were preceded by swarms of MP events with only few VTA events. Nevertheless, there were eruptions where number of VTB increased just before the eruptions: November 22, 1994, January 14, 1997 and July 11, 1998. This phenomenon shows that VT earthquake originating at Merapi Volcano plays an important role in magma migration to the surface. Unfortunately, only few studies on focal mechanism of VT earthquakes have been carried out, owing to small number of seismic stations installed on the volcano.

Increasing number of VT earthquakes since August 2000 has led up to eruption in 2001. This process is similar to that of 1992 eruption. Swarm of VT earthquakes preceded the eruptions were also observed at other volcanoes ${ }^{4,5)}$. Furthermore, to better understand the possible origin of VT earthquakes, numerous works focusing on their focal mechanism have been carried out at some volcanoes ${ }^{6-10}$.

In this paper, we analyze seismic record of VT earthquakes during the 2000 period of activity and determine their focal mechanisms. Also, we will discuss volcanological meanings of both VT earthquakes with respect to magma supply system at the volcano.

\section{Seismic observation and volcanic activity}

There were 7 permanent seismometers distributed around the volcano ${ }^{2)}$. Unfortunately, since 2000 period of activity those stations have reduced to four due to technical problem (Figure 2). Seismic station installed at PUS, the nearest station to the summit, is a three-component seismometer, while the rest are equipped with one-component (vertical) ones. Each station is equipped with $\mathrm{L} 4 \mathrm{C}$, short period $(1 \mathrm{~Hz})$ seismometer. All the seismic signals are transmitted by radio waves to Merapi Volcano Observatory (MVO), in Yogyakarta City, and continuously recorded on drum recorders. Triggered events are recorded in a PCEQ digital recording system with a sampling rate of $100 \mathrm{~Hz}$ and 12 bit resolution ${ }^{11)}$.

During January 2000 to June 2001, there were about 322 VT earthquakes $(\mathrm{VTA}=63, \mathrm{VTB}=259$ events) observed at the volcano. The daily number for these earthquakes is shown in Figure 3. Number of VT and MP events began to increase in early August 2000, but occurrence of VT ceased a few days before the eruption, meanwhile MP events still continued.

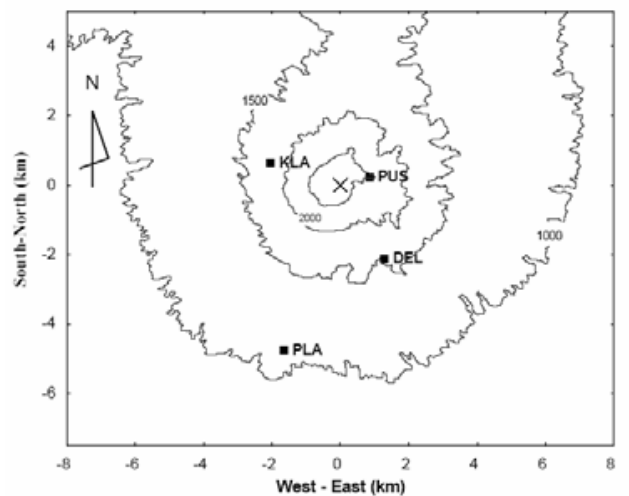

Figure 2. Location map of permanent seismic stations operated by CVGHM. Cross and solid squares indicate summit crater and seismic station.

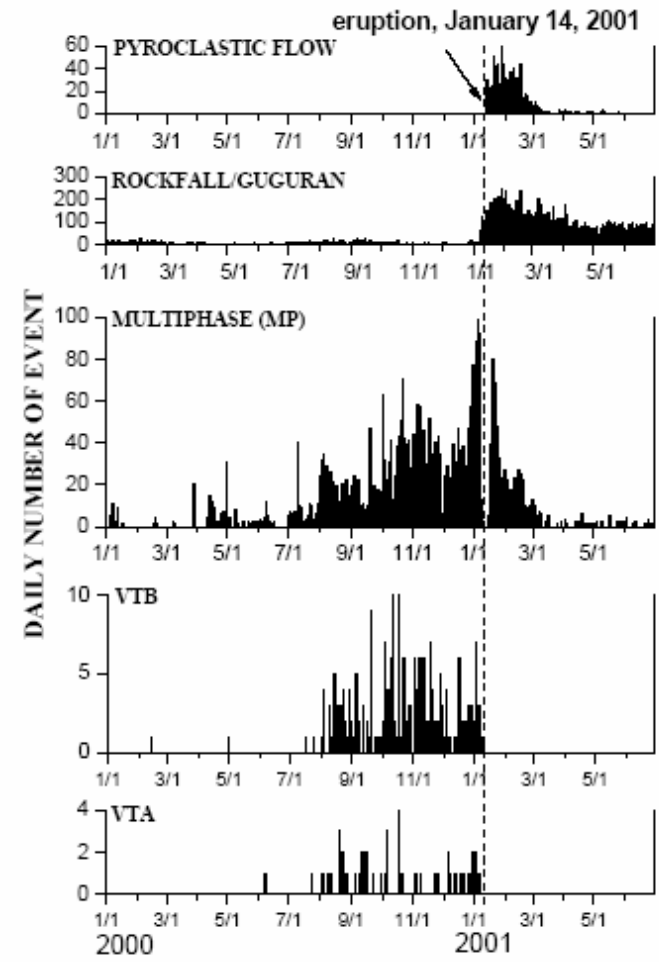

Figure 3. Daily number of seismic events at Merapi volcano recorded during period of January 2000 to June 2001. The first series of pyroclastic flows occurred on January 14, 2001.

The occurrence frequency of VTB and MP events seems to be well-correlated. In September, number of VTB and MP decreased and then both events increased again in October when significant growth of lava dome was observed. In mid December, MP events remarkably increased and reached the peak on 5 January 2001 with 99 events per day. While MP events tend to decrease, guguran started to increase on 9 January 2001. It suggests that the dome became large and unstable. On 14 January 2001, the first series of pyroclastic flows took place, whereas the occurrence of VTB had ceased in the first week of January 2001. 


\section{Data analysis}

\subsection{Characteristics of VT earthquakes}

VT earthquake originating at Merapi volcano is distinguished into 2 types, the deep (VTA) and shallow (VTB) one. For VTA, separation of P and S waves is clear and S-P time is larger than $0.5 \mathrm{~s}$. Waveform of those earthquakes are similar to that of A-type earthquakes ${ }^{12)}$, which contain high frequencies up to 8 $\mathrm{Hz}$ and show clear P- and S-phases. As for VTB, it has similar waveform and frequencies to $\mathrm{VTA}^{2)}$, but it is difficult to identify $\mathrm{S}$ waves on vertical seismograms, because of short S-P time.

Figure 4 shows each example of VTA and VTB recorded at 4 stations, PUS, KLA, DEL and PLA. The top traces (PUSN) indicate the horizontal component (N-S) at station PUS and the other traces do the vertical components at the four stations. For both events, we can identify $\mathrm{S}$ waves on horizontal seismogram at PUS. $\mathrm{S}$-P times for VTA range from $0.61 \mathrm{~s}$ to $1.14 \mathrm{~s}$, and that for VTB does from $0.1 \mathrm{~s}$ to $0.36 \mathrm{~s}$. The magnitudes of VT earthquakes have been estimated from duration time of each event ${ }^{1)}$ ranging from 1.0 to 1.4 for VTA and 1.2 to 1.6 for VTB.
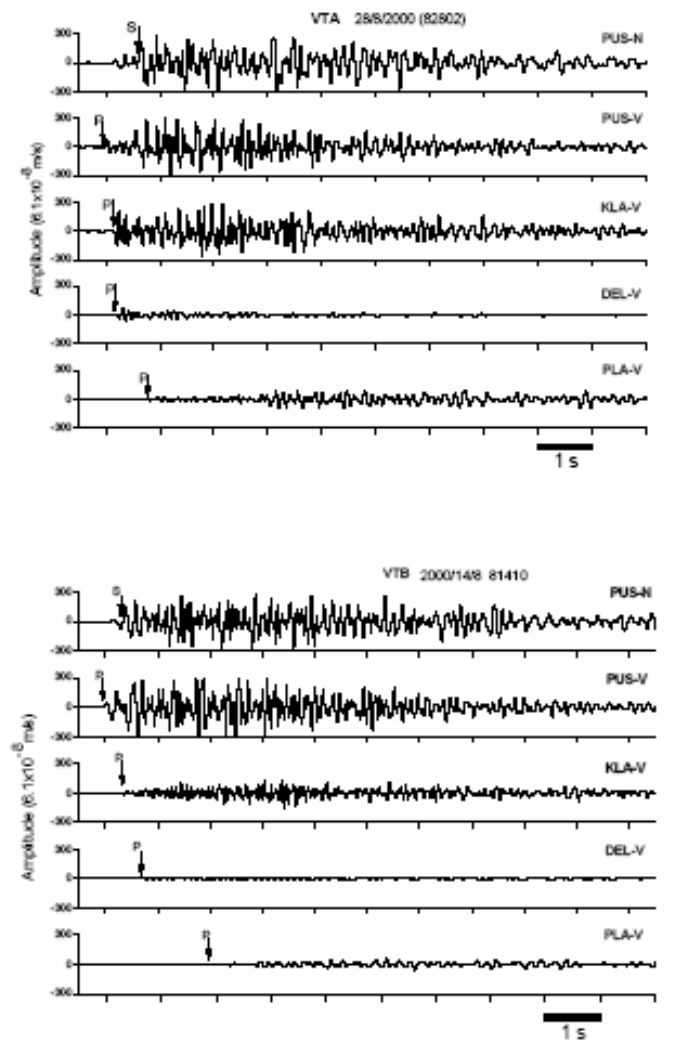

Figure 4. Waveform of VT earthquakes recorded at Merapi volcano. VTA (upper) and VTB (lower). The top traces (PUS-N) of each example indicate the horizontal component (NS) at PUS, while the rest are vertical components of PUS, KLA, DEL and PLA stations. Arrows indicate the onset of $\mathrm{P}$ waves at vertical components and $\mathrm{S}$ wave at horizontal component.
We selected 43 out of 322 VT events which were well-recorded at all four permanent stations and omitted events with reading errors of P-waves' arrival times larger than $0.01 \mathrm{~s}$ of accuracy to minimize time-picking errors.

\subsection{Location of VT earthquakes}

To locate the hypocenter of VT earthquakes a homogeneous medium with a velocity of $\mathrm{Vp}=3.0 \mathrm{~km} / \mathrm{s}$ and $\mathrm{Vs}=1.6 \mathrm{~km} / \mathrm{s}$ is assumed ${ }^{1)}$ and used $\mathrm{P}$ and $\mathrm{S}$ arrival times. Array techniques have been used during an experiment in summer 1997 evidenced apparent velocities of $2.6-3.3 \mathrm{~km} / \mathrm{s}$ for Merapi events with impulsive and first clear phases ${ }^{13)}$.

Due to small number of stations, a grid-search method is applied, using difference in relative arrival time of $\mathrm{P}$ waves between PUS and the other three stations ( $t_{p K L A}-t_{p P U S}, t_{p D E L}-t_{p P U S}$, $\left.t_{p P L A}-t_{p P U S}\right)$, and S-P time at PUS $\left(t_{s P U S}-t_{p P U S}\right)$. A uniform grid system of $x(E-W), y(N-S), z$ (depth) is defined around volcano with 100 number grid points for each direction of $\mathrm{x}, \mathrm{y}$ and $\mathrm{z}$ (interval of $0.06 \mathrm{~km}$ ). The source location is approximated by the minimum of standard deviation.

In Figure 5, hypocenters of VT earthquakes are plotted by solid and open circles for VTA and VTB, respectively. The epicenters form a cluster with radius of $1 \mathrm{~km}$ around the summit crater and the focal zone vertically extends to about $4 \mathrm{~km}$ deep beneath the summit. VTA are located at depths $2.20-4.15 \mathrm{~km}$, and VTB are at depths less than $1.30 \mathrm{~km}$. A swarm of VTB events which occurred prior to July 1998 eruption has been analyzed ${ }^{13)}$. Source of those events was detected at the depth less than $1 \mathrm{~km}$ from the summit, closely related to region of subsequent high volcanic activity.

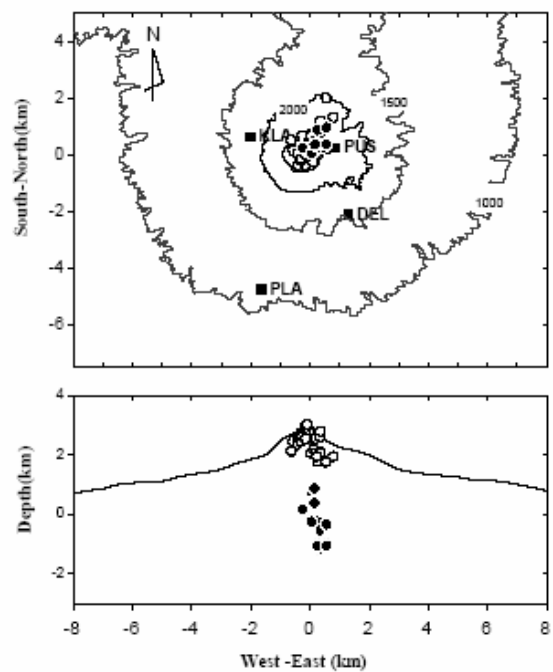

Figure 5. Hypocenters distribution of VT earthquakes. Solid and open circles represent location of VTA and VTB, respectively. Solid squares represent location of seismometers installed at Merapi volcano. PUS station is equipped with a 3-component seismometer; the rest are 1- component seismometers. 
Separation of both VT earthquakes also can be recognized from the difference in arrival time, between DEL to PUS (DEL-PUS) and PLA to PUS (PLA-PUS) as seen in Figure 6 . The figure suggests that hypocentral zone of VTA is apart from that of VTB.

There is a zone free from seismic activity between the zones of VTA and VTB, at a depth range of about 1.30- $2.20 \mathrm{~km}$ below the summit. This seismic zone coincides with that was found during period of $1991^{1)}$. It reflects that the structure beneath the volcano is somewhat stable.

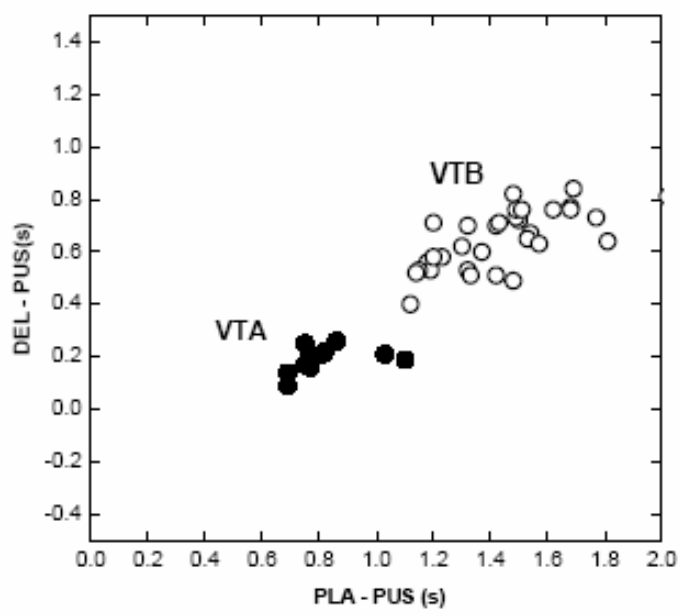

Figure 6. Difference in arrival time between PLA PUS and DEL - PUS stations recorded in 2000-2001 period of activity.

\section{3. Determination of Focal Mechanism}

Since number of seismic station is small, it is often difficult to find up a unique solution of focal mechanisms. We used both polarities and amplitudes of $\mathrm{P}$ waves' onset in order to get more stable and better constrained.

Far-field displacement of $\mathrm{P}$ wave from a point double couple source is represented by the following equation $^{14,15)}$.

$$
U^{P}(r, t)=\frac{1}{4 \pi \rho r \alpha^{3}} R^{P} \dot{M}\left(t-\frac{r}{\alpha}\right),
$$

where; $U^{P}(r, t)$ far-field displacement for P-wave, $R^{P}$ radiation pattern for $\mathrm{P}$ waves, $r$ distance, $\dot{M}$ moment rate function, $\alpha$ velocity of $\mathrm{P}$-wave, $\rho$ density (assumed to be $2500 \mathrm{~kg} / \mathrm{m}^{3}$ ).

Because we used velocity seismogram, the derivative of equation (1) is required and the equation becomes (time-term is neglected):

$$
\dot{U}^{P}=\frac{R^{P}}{4 \pi \rho r \alpha^{3}} \ddot{M}
$$

Amplitude $\left(\dot{U}^{P}\right)$ and polarity $\left(R^{P}\right)$ of first motion take an important role in determination of the mechanism, so the corrections of observed-amplitude are needed as well as calculation of radiation pattern.

The embedded effects on observed amplitude were eliminated by evaluating local site and path effects. Local site effect at each station was evaluated using seismograms of 5 tectonic events recorded at four permanent stations. These events originated on December 13, 14, 16, 17, 1997 and February 23, 1998, at about $150 \mathrm{~km} \mathrm{SW}$ from the volcano. Spectral analysis of P-wave part of the tectonic event was carried out to obtain the local site correction. Since predominant frequency of P wave for VT earthquakes is around $5 \mathrm{~Hz}$, we calculated the mean amplitudes over 4-6 $\mathrm{Hz}$ of frequency range as well as defined the ratio of amplitude at the station to that at DEL, as a reference station. DEL is situated at distance about $1.5 \mathrm{~km}$ from the crater and is characterized by minimum noise. The observed amplitude was corrected using average of ratio of those 5 tectonic events.

To remove the effect on anelastic attenuation due to property of medium, the following equation was used to correct the observed amplitude as a function of traveling distance ${ }^{14)}$.

$$
A(x)=A_{0} e^{-\left(\frac{\pi f}{Q v}\right) x}
$$

where, $A(x)$ is amplitude at a hypocentral distance $\mathrm{x}$, $A_{0}=$ amplitude at the origin of the wave, $f=$ frequency, $Q=$ attenuation factor, $v=P$-wave velocity.

Structure beneath Merapi volcano has been studied using $\mathrm{S}$-waves of an active seismic experiment ${ }^{16)}$. They obtained $\mathrm{Q}_{\mathrm{s}}$-value (scattering) around 2-10 and $\mathrm{Q}_{\mathrm{i}}$-value (intrinsic) around 100-200 at the frequency of 4-12 Hz. Q-value varies at each volcano. At Sakurajima volcano, $\mathrm{Q}_{\mathrm{p}}$ is estimated to be $20^{17)}$, Aso volcano is around $50-100^{18}$. Since we have little information about the structure beneath the volcano, the Q-value is assumed to be around 10-100. Meanwhile, correction of observed amplitude at distance $\mathrm{x}$ was made by taking into consideration that predominant frequency of VT earthquakes is $5 \mathrm{~Hz}$.

Assuming double couple sources, radiation pattern is given by the following equation ${ }^{15)}$.

$$
\begin{aligned}
R^{P}= & \cos \lambda \sin \delta \sin ^{2} i_{\xi} \sin 2\left(\phi-\phi_{s}\right)-\cos \lambda \cos \delta \sin 2 i_{\xi} \cos \left(\phi-\phi_{s}\right) \\
& +\sin \lambda \sin 2 \delta\left(\cos ^{2} i_{\xi}-\sin ^{2} i_{\xi} \sin ^{2}\left(\phi-\phi_{s}\right)\right)+\sin \lambda \cos 2 \delta \sin 2 i_{\xi} \sin \left(\phi-\phi_{s}\right)
\end{aligned}
$$


Indonesian Journal of Physics

Vol 19 No. 3, July 2008

where $\phi_{\mathrm{s}}, \delta$ and $\lambda$ represent strike, dip and rake of the fault plane, while $\phi$ and $i_{\xi}$ do azimuth and take off angle of the source, respectively. Based on polarity and amplitude of P-wave first motion, strike, dip and rake, a grid search is determined. The equation (2) is simplified to minimize standard deviation of error for linear approximation between observational ground velocity $\dot{U}^{P}$ and calculated velocity $\frac{R^{P}}{4 \pi r \rho \alpha^{3}}$.

A grid over $\phi_{s}, \delta$ and $\lambda$ with 3 degrees resolution is defined. $\phi$ and $i_{\xi}$ for each station are obtained by hypocenter calculation.

Figure 7 shows focal mechanism solutions projected on upper hemisphere of the focal sphere for 12 VTA events. The value of first motion observed-corrected amplitude and calculated one for each station is also shown on the focal sphere. Most of the solutions, 11 out of 12 are normal fault types, had T-axes nearly horizontal with NEE-SWW direction. The distribution of $\mathrm{P}$ - and $\mathrm{T}$-axes of their focal mechanism is shown in Figure 8.
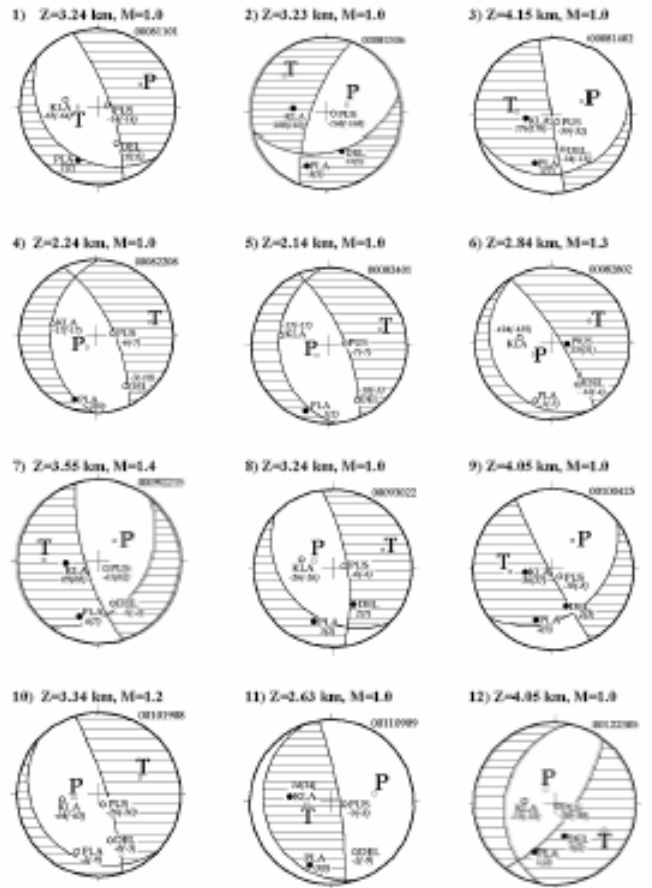

Figure 7. Focal mechanism of VTA earthquakes at Merapi volcano. Seismic stations that recorded compressional and dilatational waves are denoted in upper hemisphere stereogram by solid and open circles, respectively. Numbers (in 10-8 m/s) correspond to first motion observed-corrected amplitude and the calculated one (in brackets). $\mathrm{Z}$ and $\mathrm{M}$ in each focal sphere indicates depth and magnitude, respectively.

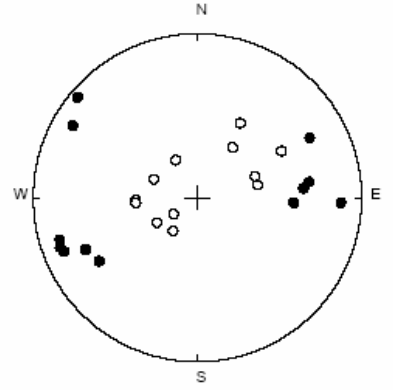

Figure 8. Projection of compression (P) and tension (T) axes of the focal mechanisms for 12 VTA events. Open and solid circles denote the P- and T-axes, respectively.

As for VTB, we could determine focal mechanism of 19 events. Each solutions of focal mechanism are arranged from shallower to deeper location in Figure 9. The focal mechanism of VTB events deeper than $0.70 \mathrm{~km}$ (No. 14-19) was dominated by normal fault type. On the other hand, at the shallower depth (No. 1-13), reverse fault, normal fault and strike slip types were observed. The orientation of their P-and T-axes is shown in Figure 10.

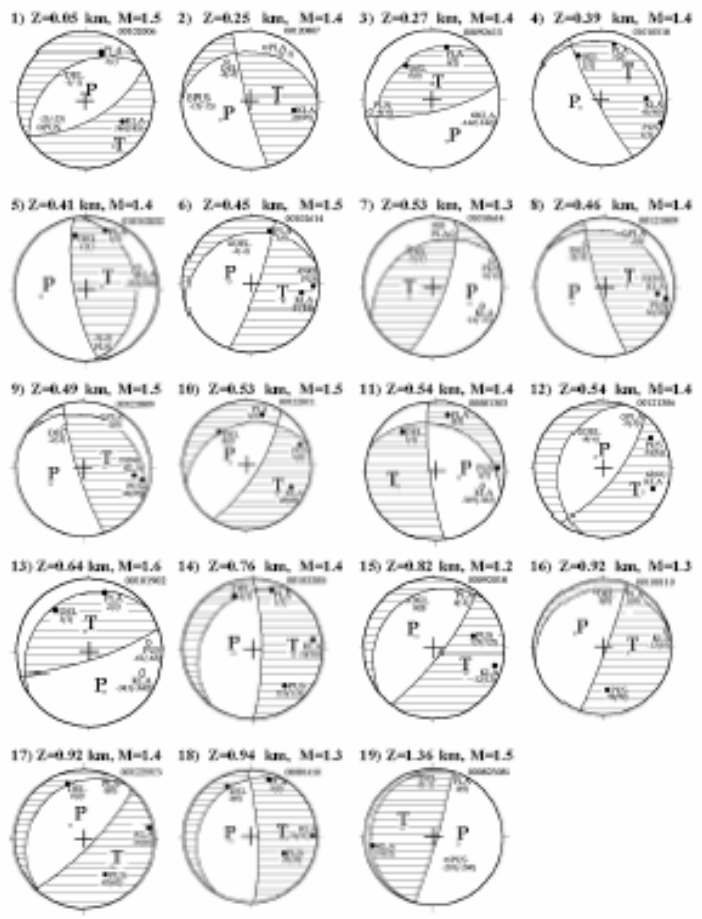

Figure 9. Possible focal mechanism of VTB recorded at Merapi volcano. Seismic stations that recorded compressional and dilatational waves are denoted on upper hemisphere stereogram by solid and open circles, respectively. The downgoing ray is re-mapped onto upper hemisphere by simply adding 180 o to all stations azimuth. Numbers (in $10-10 \mathrm{~m} / \mathrm{s}$ ) correspond to first motion observed-corrected amplitude and the 
calculated one (in brackets). Open squares denote pressure $(\mathrm{P})$ and tension $(\mathrm{T})$ axes.

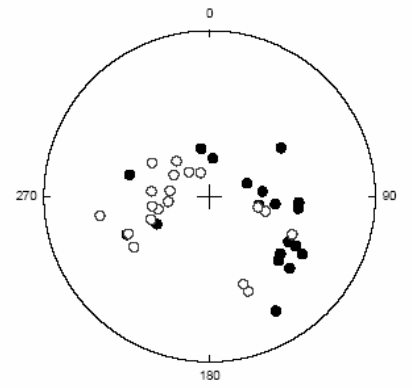

Figure 10. Projection of compression (P) and tension (T) axes of the focal mechanism for VTB. Open and solid circles denote the P-and -Taxes, respectively.

Since we only could determine focal mechanism 12 events for VTA and 19 for VTB, so, we evaluate these results using polarities of the first arrival at PUS, the closest station to summit crater. All VT earthquakes are examined. Figure 11 shows histogram distribution of those polarities explaining that polarity of VTA is mostly dilatation ("pull”), while for VTB is mostly compression ("push”). For VTA, 39 out of 51 events (77\%) showed dilatation, 8 (16 \%) were compression and the rest is unknown. As for VTB, 149 out of 208 events showed compression, 42 events showed dilation and 17 events were unknown.

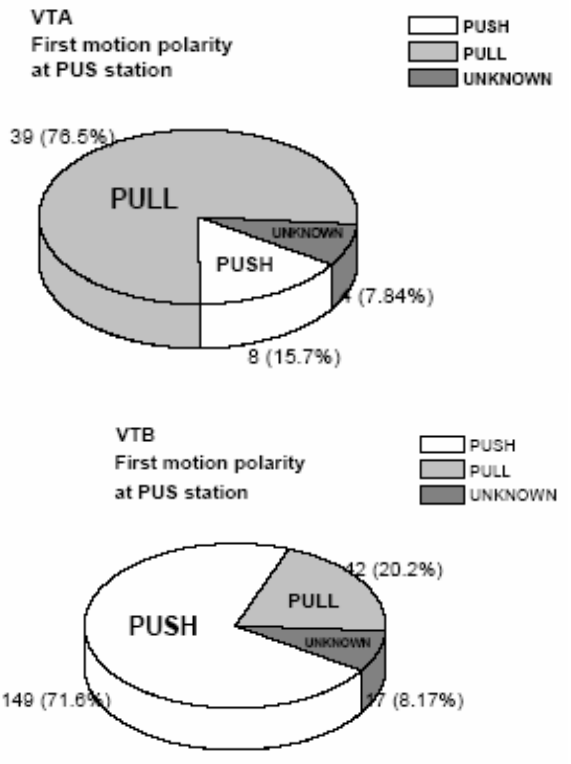

Figure 11. Distribution of first motion polarity of VT earthquakes observed at PUS station. VTA (upper) and VTB (lower).

\section{Discussion and Conclusion}

We determined hypocenters of VT earthquakes originating at Merapi volcano prior to the 2001 eruption and estimated their focal mechanisms. In this section, we will discuss about magma supply system and source mechanism of the VT earthquakes in relation with process of magma migration and eruptive activity as well.

The image of magma supply system of Merapi volcano based on previous studies and the result of this study is illustrated in Figure 12. The seismic zone of VT earthquakes vertically extends to about $4 \mathrm{~km}$ deep beneath the summit, and there is an aseismic zone at a depth range of about $1.30-2.20 \mathrm{~km}$ between the two types of those earthquakes. It is proposed as temporary magma storage before extrusion to the summit ${ }^{1)}$. It should be emphasized that seismic activity in the vertically extended zone has increased prior to eruption.

Ground-tilt data during the period from 1995 to 1997 have been analyzed ${ }^{19)}$ and found pressure source in three ranges of depth below the summit, namely, 3.8 $\mathrm{km}, 1.7 \mathrm{~km}$ and $0.4-0.7 \mathrm{~km}$. It is noteworthy that pressure source migrated from deeper to shallow portion, and tilt change at the nearest station to the summit was accelerated a few months before the explosive eruption in January, 1997. The deepest location of pressure source is located where deepest VTA events were originated. Degassing depth of Merapi magma inferred from $\mathrm{CO}_{2} / \mathrm{H}_{2} \mathrm{O}$ ratio in fumarolic gas is located at $1.0-1.7 \mathrm{~km}^{20}$. This range of depth approximately coincides with an aseismic zone to deeper zone of VTB events.

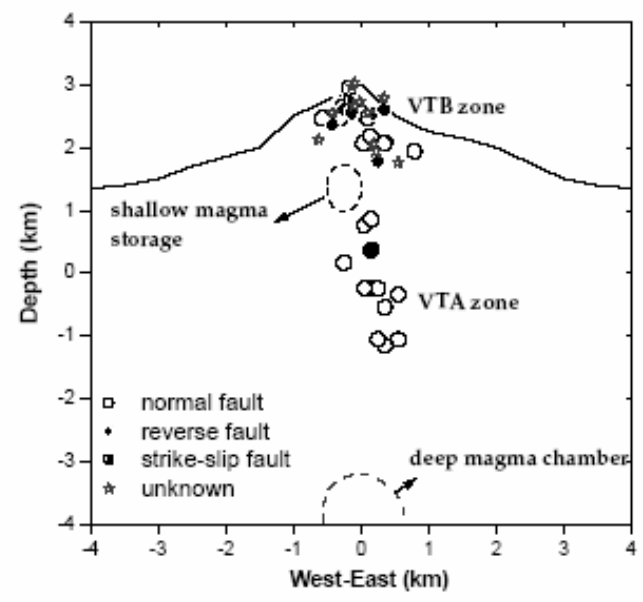

Figure 12. Sketch showing the magma supply system at Merapi volcano. Open, solid, half-shaded circles and stars indicate normal fault, reverse fault, strike slip fault types and unknown mechanism, respectively.

These geodetic and geochemical studies suggest that seismic zone of VTA event is originated between the deepest pressure source ${ }^{19)}$ and the shallow magma storage. VTA events are thought to be mainly related to intrusion of magma. When pressure increases at deep magma reservoir and ascents through the conduit, horizontal tension would be induced ${ }^{9)}$. Then, this pressure change may produce VTA events of normal-fault type. 
Moreover, in Central Java, there is a chain of volcanoes aligned from north to south, Ungaran, Soropati, Telomoyo, Merbabu and Merapi (Figure 1). This may suggest that tension of east to west direction is predominant in the area. The orientation of T-axes of VTA events is nearly horizontal and perpendicular to the chain of the volcanoes. Thus, the mechanism of VTA events might be partly affected by regional tectonic stress with NEE-SWW extension.

Possible solution of focal mechanism for VTB as seen in Figure 9 is composed of normal, reverse and strike slip fault types. Most of deeper VTB events have focal mechanism of normal fault type, and the shallower ones have various focal mechanisms. To discuss the volcanological implication of focal mechanism of VTB events, we examined state of shallow part of the volcano from other information.

Pressure source $1.7 \mathrm{~km}$ deep $^{19)}$ is located within area of seismicity gap between VTA and VTB zones, while the depth of shallowest one is shallower than aseismic zone itself. It suggests that the increased of pressure source occurs not only at the uppermost part of aseismic zone but also in the VTB seismic one. As pressure increased at the shallow magma storage may cause increase in horizontal tension around it and deep VTB events of normal fault could be generated, as similar way as VTA events. Furthermore, degassing depth ${ }^{20)}$ also passes through the deeper VTB zone. Degassing process might induce horizontal compression by pressure decrease due to escape of volcanic gases from magma conduit.

At shallower VTB zone $(<0.7 \mathrm{~km})$, the mechanism is mostly composed of both reverse fault and normal fault types. The occurrence of VTB events seems to be closely related to increase of MP events which are associated with lava dome formation, namely extrusion of magma. Extrusion of magma may induce pressure decrease in magma conduit, thus, the VTB of reverse fault might be originated. In contrast, pressure increases at shallowest pressure source due to accumulation of volcanic gases or magma, may cause the generation of VTB of normal fault type. It suggests that shallow part of Merapi volcano in the active period is under complicated state.

Note in Figure 13 that VTB and MP events increased and decreased in similar trend. Occurrence of VTB event of "pull" type sometime interfered by the "push" one. The "pull” type relatively increased 2 weeks before the first series of pyroclastic flows that took place on January 14, 2001. It is inferred that pressure increase and decrease alternately occur at the shallow seismic zone of VTB events, and both normal-fault type and reverse-fault type earthquakes may be originated, as also observed at Sakurajima volcano ${ }^{6)}$.

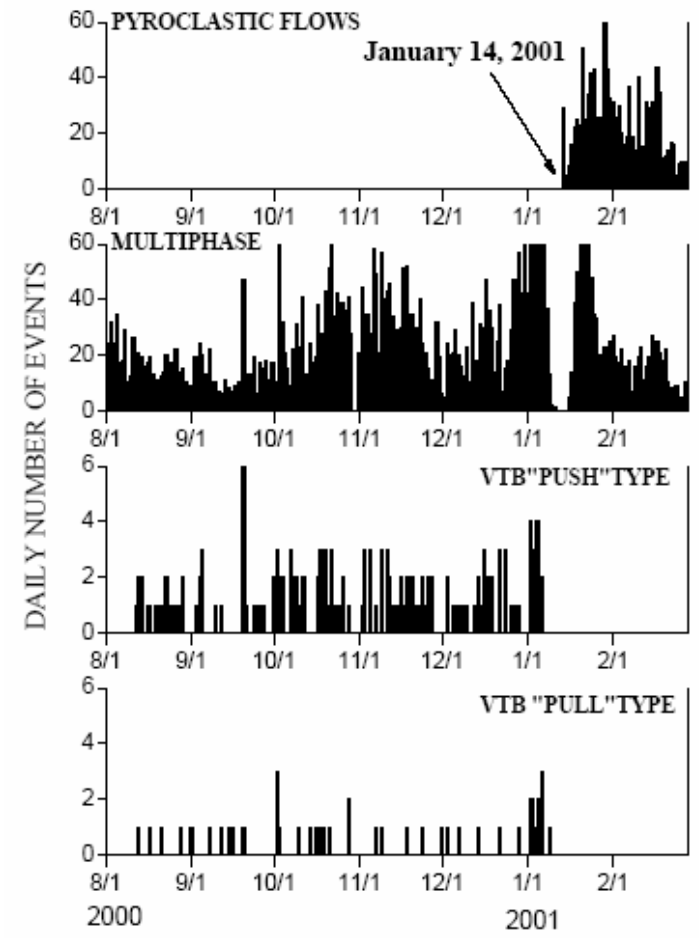

Figure 13. VTB and MP events increased and decreased in similar trend. VTB of "pull" type relatively increased 2 weeks before the first series of pyroclastic flows on January 14, 2001.

However, it is not easy to judge the exact mechanism of VT events at Merapi volcano. The difficulty may be related to a small number of seismic stations as well as the assumed velocity structure, since we have little information on substructure of the volcano.

In summary, the occurrence of VT earthquakes at Merapi volcano has marked a new beginning of eruptive activity. Since increasing number of those earthquakes since August 2000 has led up to an eruptive episode in January 2001. An aseismic zone was recognized at the depth about $1.30-2.20 \mathrm{~km}$ from the summit between the VTA and VTB zones, as supposed to be small magma storage, where magma stays for a while. We may conclude that there is no significantly difference of VT earthquakes distribution in period $1991^{1)}$ and 2000 . This suggests that magma supply system has essentially not varied since 1990 .

\section{Acknowledgments}

Thank to Mr. Suharno of Merapi Volcano Observatory (of CVGHM) for providing the database of Merapi volcano. The SISMALP software is from LGIT-Grenoble, France. Special thanks due to Drs Keigo Yamamoto and Takeshi Tameguri of Sakurajima Volcano Research Center, Kyoto University for their worthy comments. 


\section{References}

1. A. Ratdomopurbo, Etude Sismoloique du Vulcan Merapi et Formation du dome de 1994, PhD Thesis, L'universite Joseph Fourier-Grenoble I, France. 1995.

2. A. Ratdomopurbo, and G. Poupinet, An Overview of the Seismicity of Merapi, Java, Indonesia, 1983-1994, J.Volcanol.Geotherm.Res., 100, 193-214, 2000.

3. S. Hidayati, et al., A Preliminary result of quantitative evaluation on activity of Merapi volcano, Symposium on Japan-Indonesia IDNDR Project (September,21-23,1998, Bandung, Indonesia), 165-180, 1998.

4. Ph. Lesage and Surono, Seismic Precursors of the February 10, 1990 eruption of Kelut volcano, Java, J.Volcanol.Geotherm.Res., 112, 37-52, 1995.

5. V.M. Zobin, et al., Comparative Characteristics of the 1997-1998 Seismic Swarms Preceding the November 1998 Eruption of Volcan de Colima, Mexico, J.Volcanol.Geotherm.Res., 117, 47-60, 2002.

6. K. Nishi, On the Focal Mechanism of Volcanic Earthquakes in Sakurajima Volcano, Ann.Dist.Prev.Res.Inst. Kyoto.Univ.Japan, 21, 145-152, 1978. (in Japanese, with English Abstr.)

7. T. Wada, Focal Mechanism of Volcanic Earthquakes, Ann. Dist. Prev. Res. Inst. Kyoto Univ. Japan., 32, 23-28, 1989. (in Japanese, with English Abstr.)

8. O. Cocina, et al., Seismogenic Stress Field Beneath Mt. Etna and Possible Relationships with Volcano-tectonic Features, J.Volcanol.Geotherm. Res., 83, 335-348, 1998.

9. D. Patane and E. Privitera, Seismicity Related to 1989 and 1991-93 Mt. Etna Eruptions: Kinematic Constraint by Fault Plane Solution Analysis, J.Volcanol.Geotherm.Res., 109, 77-98, 2001.

10. K. Umakoshi, H. Shimizu, and N. Matsuwo, Volcano-tectonic Seismicity at Unzen Volcano, Japan, 1985 - 1999, J. Volcanol. Geotherm. Res., 112, 117-131, 2001.
11. H.W.K. Lee, Toolbox for Seismic Data Acquisition, Processing and Analysis, IASPEI Software Library I, Seismological Society America, Berkeley, CA, USA, 1989.

12. T. Minakami, Seismology and Volcanoes in Japan. In Physical Volcanology (Civetta, L., Gasparini, P., Luongo, G., Rapolla, A., eds), 1-27. Elsevier, 1974.

13. Wasserman, J and Ohrnberger, M., (Automatic hypocenter determination of volcano induced seismic transients based on wavefield coherence--an application to the 1998 eruption of Mt. Merapi, Indonesia), J. Volcanol. Geotherm. Res., 110, 57-77, 2001.

14. Lay, T. and Wallace, T.C. Modern Global Seismology, Academic Press. California. 1995

15. Aki, K. and Richards, P.G. Quantitative Seismology, W.H. Freeman and Company. San Fransisco. 1980

16. Wegler, U and Luhr,B.G., (Scattering Behaviour at Merapi volcano (Java) revealed from an active seismic experiment), Geophys.J.Int., 145, 579-59, 2001.

17. Iguchi, M., (A vertical expansion source model for the mechanisms of earthquakes originated in the magma conduit of an andesitic volcano: Sakurajima, Japan), Bull.Volcanol.Soc.Japan., 39, 49-67, 1994.

18. Sudo, Y., (An attenuation structure beneath the Aso Caldera determined from the propagation of seismic waves), Bull. Volcanology., 53, 99-111, 1991.

19. Subandriyo, Purbawinata, M.A., Iguchi, M., Ishihara, K., Young, K.D., Voight, B., (Characteristic of Tilt Changes in associated with Merapi eruption during the 1993-1997 eruption), Symposium on Japan-Indonesia IDNDR Project (September 21-23, 1998 Bandung, Indonesia), 155-163, 1998.

20. Hirabayashi, J., Ohba,T., Sukhyar,R., Sano,Y., (Chemistry of volcanic gases from Jawa), Symposium on Japan-Indonesia IDNDR Project (September, 21-23, 1998, Bandung, Indonesia), 51-56, 1998. 